\title{
Growth of mixed materials in the Be/W/O system in fusion devices
}

\author{
Mateus, R. , Carvalho, P.A. , Franco, N. ${ }^{*}$, Alves, E. ${ }^{*}$, Porosnicu, C. ${ }^{* *}$ and Lungu, C.P.** \\ Associação Euratom/IST, Instituto de Plasmas e Fusão Nuclear, Instituto Superior Técnico, \\ Universidade de Lisboa, 1049-001 Lisboa, Portugal \\ *** Association EURATOM-MEdC, National Institute of Lasers, Plasma and Radiation Physics, 077125 \\ Bucharest, Romania \\ Email: rmateus@ipfn.ist.utl.pt
}

Beryllium (Be) and tungsten (W) will be used as plasma facing materials in the next future in fusion reactors with the purpose to take advantage from the individual properties of each metal. Nevertheless, different events will take place during reactor operation such as erosion of the exposed surfaces, transport of impurities in the main plasma and re-deposition of the eroded material in other locations. Moreover, the heat load in the reactor walls and the kinetic energy of the impinging particles will induce the formation of Be-W intermetallics and oxides, where oxygen $(\mathrm{O})$ acts as a contaminant. As a consequence, the chemical, physical and the mechanical properties of the exposed surfaces may evolve over time, and the formation of new phases should be investigated [1,2] in order to predict the lifetime of the parts under plasma exposure.

In this work, Be and $\mathrm{W}$ films with thicknesses of 100 and $200 \mathrm{~nm}$ were deposited on $\mathrm{W}$ and Be plates, respectively, by using the thermionic vacuum arc (TVA) method [1]. Afterwards, the samples were annealed in vacuum at different temperatures and analysed with ion and electron beam techniques for elemental quantification, and by grazing X-ray diffraction (XRD) for phase identification [2]. The use of ion beam techniques is particular important in the study of Be samples, while Be is not detected by EDS. Electron microscopy images were collected with secondary (SE) and backscattering electrons (BSE) for topographic and chemical analysis, respectively. Energy-dispersive X-ray spectrometry (EDS) was also carried out for elemental quantification and mapping.

All the experiments performed in the four batches lead us to the same conclusions. The Be-W reactivity is very weak up to $700^{\circ} \mathrm{C}$ and it becomes very fast at $800^{\circ} \mathrm{C}$, leading to a strong $\mathrm{Be}-\mathrm{W}$ interdiffusion and compound formation, being the growth of $\mathrm{Be}_{2} \mathrm{~W}$ and $\mathrm{Be}_{12} \mathrm{~W}$ identified by $\mathrm{XRD}$. The Be-W reactivity is accomplished with the formation of a $\mathrm{BeO}$ superficial layer, as it is concluded from EDS mapping, due to the affinity of Be to react with $\mathrm{O}$. In the case of $\mathrm{W}$ films deposited on Be plates, ion beam analysis evidence that, typically, Be diffuses through the superficial W layers and oxidizes at the surface.

A smooth delamination behaviour induced by thermal stress was observed in the Be films after annealing at higher temperatures. The $\mathrm{Be}-\mathrm{W}$ interdiffusion and the growth of the intermetallic components may be followed by the chemical analysis of the delaminated zones. Fig. 1a shows one of these events occurred at $700^{\circ} \mathrm{C}$ in the $200 \mathrm{~nm} \mathrm{Be}$ batch, where the formation of a new phase is starting along the edge of the delaminated area. From the comparison of both SE and BSE images in Fig. 1b and 1c, we conclude that the new phase has a high $\mathrm{W}$ content. After annealing at $800^{\circ} \mathrm{C}$, all the delaminated areas become covered with the new component (Fig. 1d), which starts to grow up along the entire annealed surface (Fig. 1e and 1f). Additionally, EDS data reveal that the formation of $\mathrm{BeO}$ is homogeneously distributed in the surface and it is enhanced at higher temperatures (Fig. 2), while the corresponding diffractograms evidence that $\mathrm{BeO}$ seems to be restricted to a very thin and superficial layer, and that $\mathrm{Be}_{12} \mathrm{~W}$ is the main intermetallic composition up to $800^{\circ} \mathrm{C}$.

This work has been carried out in the frame of the contracts of association between EURATOM, IST (Portugal) and MEdC (Romania). 
[1] Porosnicu C. et al., Journal of Nuclear Materials, 415, S713-S716, 2011.

[2] Mateus R. et al., Journal of Nuclear Materials, 442, S320-S324, 2013.
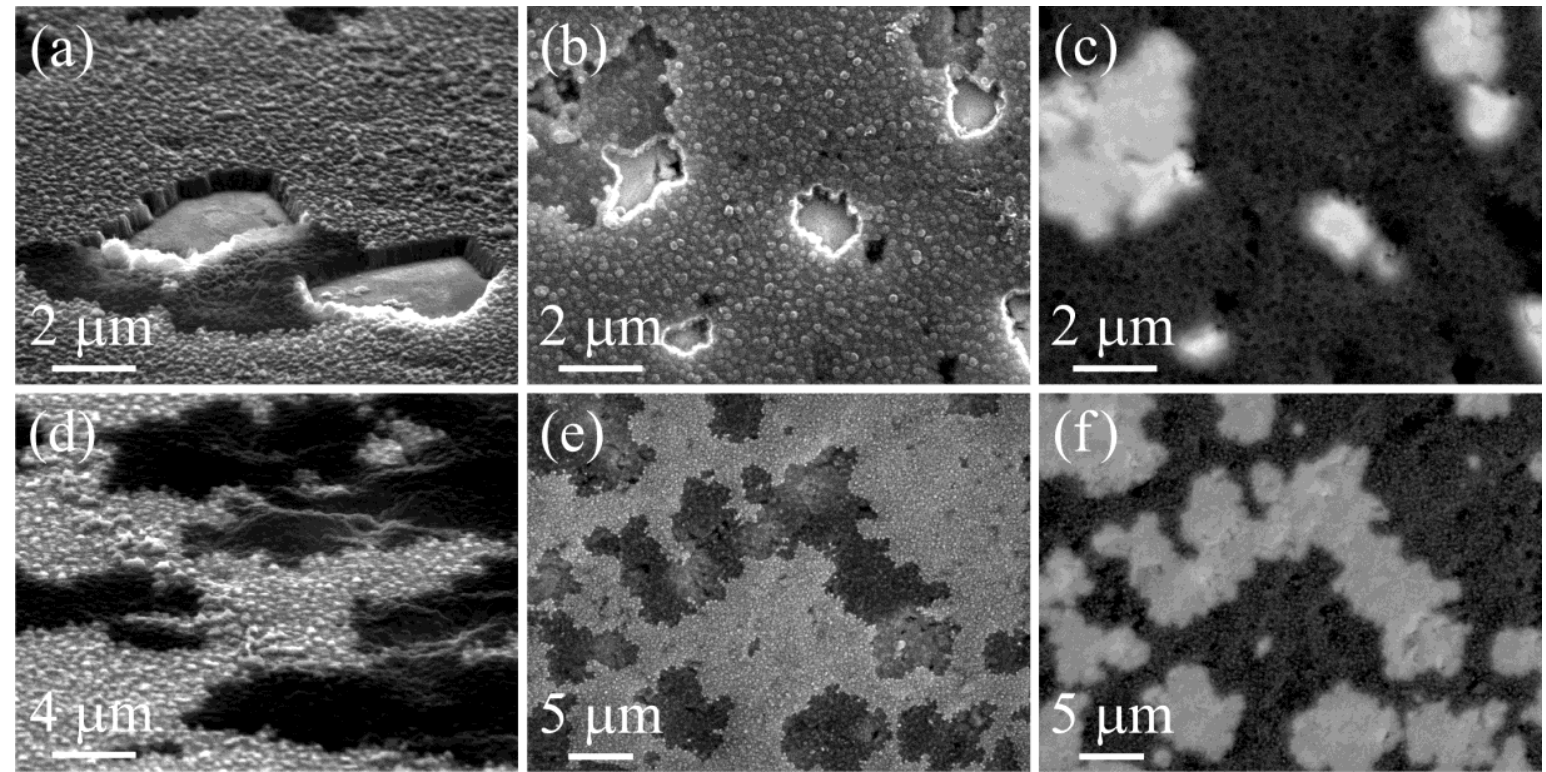

Figure 1. SE tilted view of a delaminated zone (a) and corresponding SE (b) and BSE (c) top views obtained from the $200 \mathrm{~nm}$ Be film deposited on $\mathrm{W}$ after annealing at $700^{\circ} \mathrm{C} / 4 \mathrm{~h}$; similar images obtained from the same batch after annealing at $800^{\circ} \mathrm{C} / 4 \mathrm{~h}$ in (d), (e) and (f).

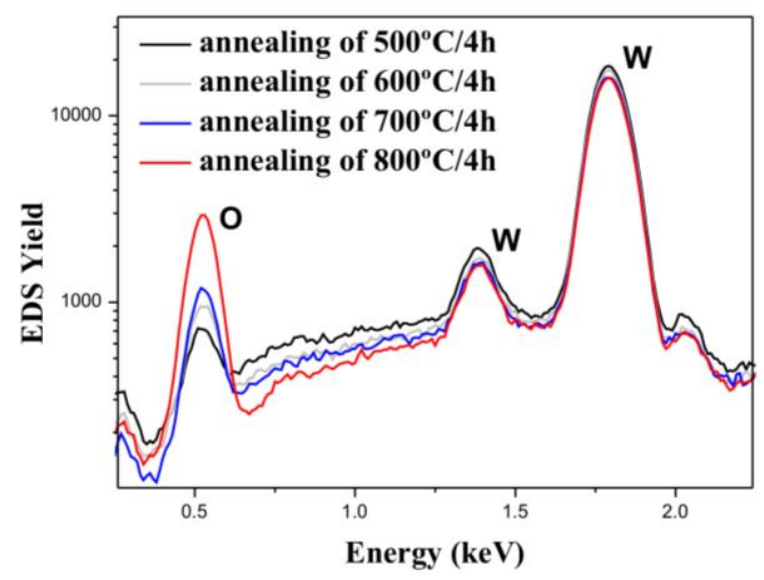

Figure 2. EDS spectra collected from the $200 \mathrm{~nm}$ Be batch after annealing (colours online).

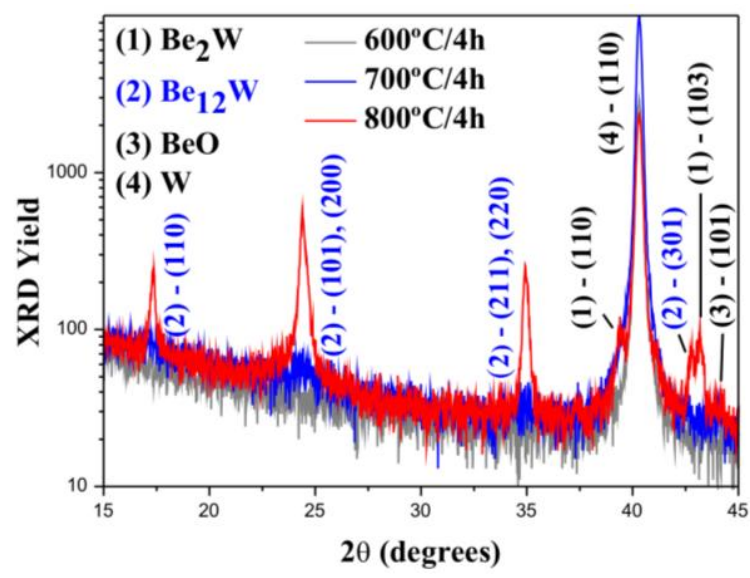

Figure 3. XRD spectra collected from the $200 \mathrm{~nm}$ Be batch after annealing (colours online). 